Original Research Paper

\title{
A Novel Method to Improve Weld Uniformity by Automatic Control of Current Intensity
}

\author{
${ }^{1}$ Abdul Aziz A. Morgan and ${ }^{2}$ Fahad A. Al-Mufadi \\ ${ }^{I}$ Department of Mechanical Engineering, Ain Shams University, Cairo, Egypt \\ ${ }^{2}$ Department of Mechanical Engineering, Qassim University, Buraydah, Saudi Arabia
}

\author{
Article history \\ Received: 14-02-2014 \\ Revised: 29-09-2014 \\ Accepted: 27-12-2014 \\ Corresponding Author: \\ Fahad A. Al-Mufadi, \\ Department of Mechanical \\ Engineering, Qassim University, \\ Buraydah, Saudi Arabia \\ Email: almufadi@qec.edu.sa
}

\begin{abstract}
This study aims to develop an automatic arc welding system capable of welding irregular and moving joints which are difficult to weld manually. The motivation of this research comes from the need to produce uniforms weldings on regular and irregular surfaces by automatic means. The system consists of a personal computer equipped with $A / D$ interface card connected to an electric current sensor and two electric motors controlled via electronic circuits. A control program receives the electric current measurements and makes the necessary calculations for the correct vertical motion of the welding electrode. A modified PID controller was used to control the process dynamics. An X-Y mechanism with two electric motors was developed to control the motion of the electrode as well as the work piece. A comparison was made between two welded specimens; one was welded by traditional manual method and, the second by using automatic control mechanism. The weld distribution through the welded joints was compared. Different irregular joints were also compared for the manual and automatic control welding methods. It was found that the control system works with an accuracy of $\pm 28 \mu \mathrm{m}$ for a $1.01 \mathrm{~mm}$ weld thickness of a flat weld by controlling the current at $60 \mathrm{~A}$ within a standard deviation of $\pm 1.45 \mathrm{~A}$. As a result welds with uniform thickness were obtained. The uniform heating further contributes to a uniform microstructure in the weld area. The implications of this research will be enhanced automation of the welding process in industry, with improved control over its uniformity, especially while welding around circular objects and during vibrating or unstable conditions.
\end{abstract}

Keywords: Welding Joints, Welding Control, Arc Welding, Uniform welding

\section{Introduction}

Welding operations are required in manufacturing operations, virtually all modern products. Therefore, many researchers have tried to develop the technology to suit different welding and soldering connections on irregular surfaces as well as joints on unstable surfaces. Electric arc welding automation is especially important, as it requires high skill which may not be available in sufficient numbers in many applications such as shipbuilding and fuel tanks. Robot welding has become a necessity of the industry in many areas of modern manufacturing.

Automatic control of arc welding is an area of prime interest for researchers and industrialists alike. The current research attempts to use a novel method to control the thickness of the weld through controlling the current. The aim is to get uniform and homogeneous welding under any complications including vibrations and non-uniform surface. This research will contribute to good quality joints in arc welding that will lead to raise the strength of cohesion of these joints and making homogeneous mechanical properties of the weld.

\section{Objectives}

The objective of this research is the development of a welding technology with automatic control through a computer program. The program can produce welding with homogeneous thickness. This is done by measuring the intensity of the current through the control card and controlling the distance between the welding rod and the part to make welding consistent. 


\section{Aims:}

- To control the thickness of the electric arc weld by measuring the severity of the current that is obtained through the welding

- To produce an electric arc weld with constant heating rates, which should lead to uniform microstructure throughout the weld

- To produce an integrated system of welding to carry out control and coordination between the welding machine and axes movements of the welding rod holder

\section{Literature Review}

Automatic control of welding has been of prime interest to many researchers around the world. Some researchers have suggested using ultrasound to control the depth of the welding joints (Umeagukwu et al., 1989). Other researchers are using lasers to automatically follow the welding (Umeagukwu and McCormick, 1991) or to analyze the image area to control the welding rod for welding a work piece (Nied and Baheti, 1986). There is research on the control of welding rod based on measuring the temperature of the molten metal (Doumanidis, 1993) and also on multivariable adaptive control of the bead profile geometry (Doumanidis and Kwak, 2002). Researchers have also analyzed the light reflections caused by the welding process to determine the length of the electric arc and then control the welding rod ( $\mathrm{Li}$ and Zhang, 2001). Advanced materials like Ti-6Al-4V have been welded by controlled plasma arc welding process (Chen and Pan, 2011). While others have used fuzzy logic to spatial thermal control in fusion welding (Bingül et al., 2000). Machine recognition of laser reflection from gas metal arc weld pool surfaces was carried out as well (Wang et al., 2011). Design and validation of a sensor guided robot control system for welding in shipbuilding was done by Fridenfalk and Bolmsj (2002). Control of arc gap through robotic TIG welding was done by Karafi et al. (2010). Current and voltage control have been exercised in Gas Metal Arc Welding Process (Anzehaee and Haeri, 2011). Many researchers have used weld bead as a control parameter (Murugana and Gunaraj, 2005). While others have used pool geometry as a control parameter (Bae et al., 2002). Weld penetration has been controlled dynamically by others (Zhang and Liu, 2007). Other researchers have used artificial intelligence techniques of neural networks for welding control (Kima et al., 2004).

\section{Research Design and Methodology}

\section{Introduction}

The experimental apparatus is described below and is shown in Fig. 1. The machine has a built in control for the horizontal and vertical axis. The welding rod holder is controlled in the vertical direction by a stepper motor Size
23 (1.63 NM, 1.80 step angle) and horizontal direction by a stepper Size 34, 4.8 NM, which can be controlled through a computer. The control is implemented with an automatic control card which can control the inputs and outputs with high accuracy control program.

The components of the control system are listed below:

- An electronic circuit to control the current

- A control program in Visual basic language

- A control card with a computer

\section{Experimental Design}

Two different experiments were carried out and compared:

- A standard weld on a flat surface

- A weld on an irregular surface

Comparison was carried out between the joints in terms of the strength of the connections and the mechanical properties.

\section{Experimental Apparatus}

A machine was used to control the X-Y axes with high accuracy. The device has a table that can hold samples to be welded as shown in Fig. 1. Also a conductor device with electronic control circuitry is connected to measure the intensity of the welding current.

A program was written for computer to control the outputs and inputs in the electronic control card. Also linked to a computer are: Card control and electronic circuits for controlling the welding rod holder and the movement of the work piece.

\section{Experimental Test Rig}

To accomplish the research objectives, the electronics shown in Fig. 2 was designed and assembled. The figure shows the electronic control circuit with a digital oscilloscope hooked up with a PC for data acquisition. The control circuit is connected with the electric current sensors of welding machine and stepper motors.

Figure 3 shows the welding mechanism with two axis of motion in action.

Figure 4 shows the stepper motor control circuit. An interface 12 bin ADA card was used to allow the personal computer to read voltage and control the stepper motor rotation and direction.

\section{Control Loop}

The schematic diagram of tracking feedback control loop is shown in Fig. 5. The control in this study has been provided by parallel type digital PID (proportionalintegral-derivative) controller with anti wind up scheme. PID controllers posses the property of ease with which the parametric control can be achieved and they also are used in more than $95 \%$ of closed loop industrial process (Astrom and Hagglund, 1995). 


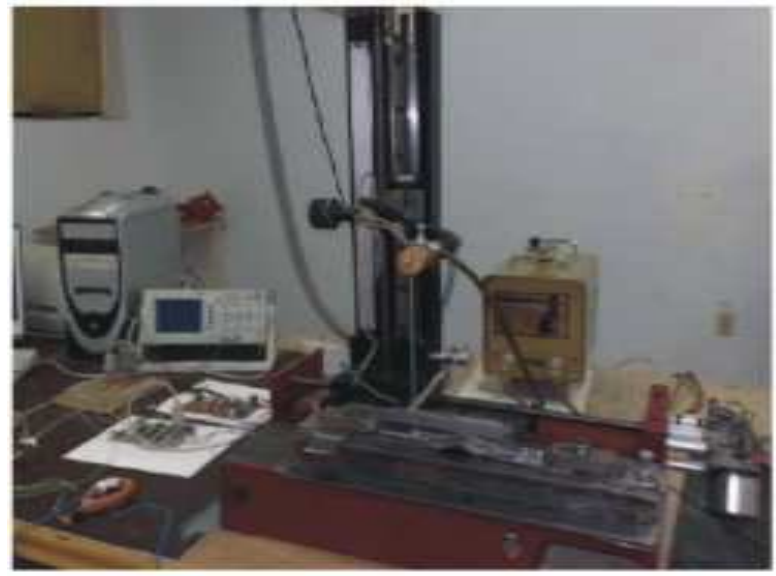

Fig. 1. Configuration of the welding test rig

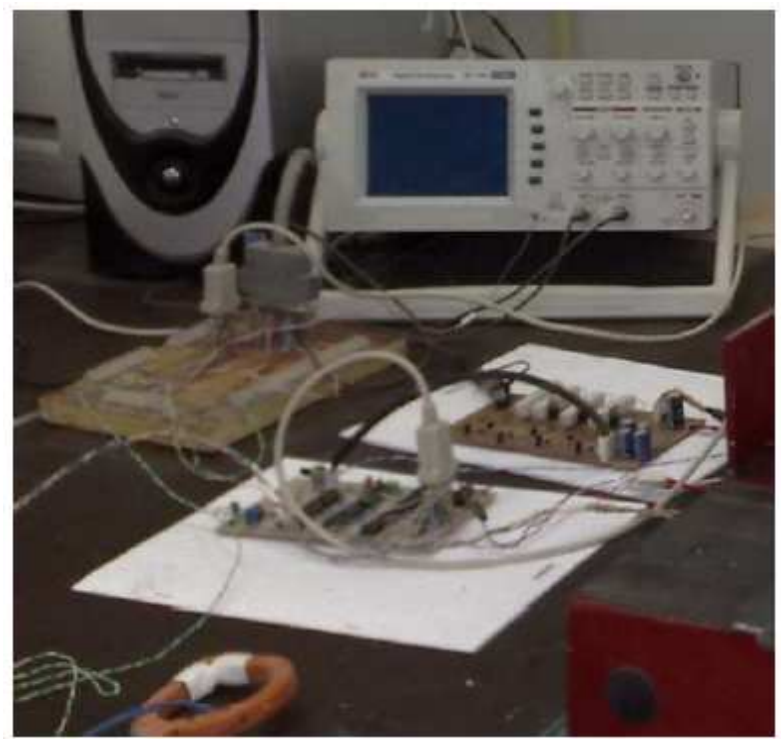

Fig. 2. Welding current electronic control circuit

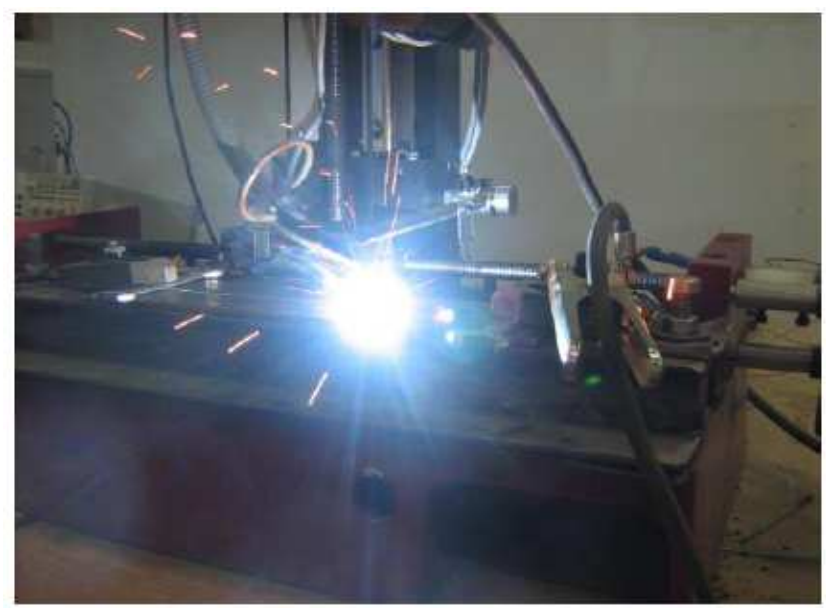

Fig. 3. Experimental test rig 


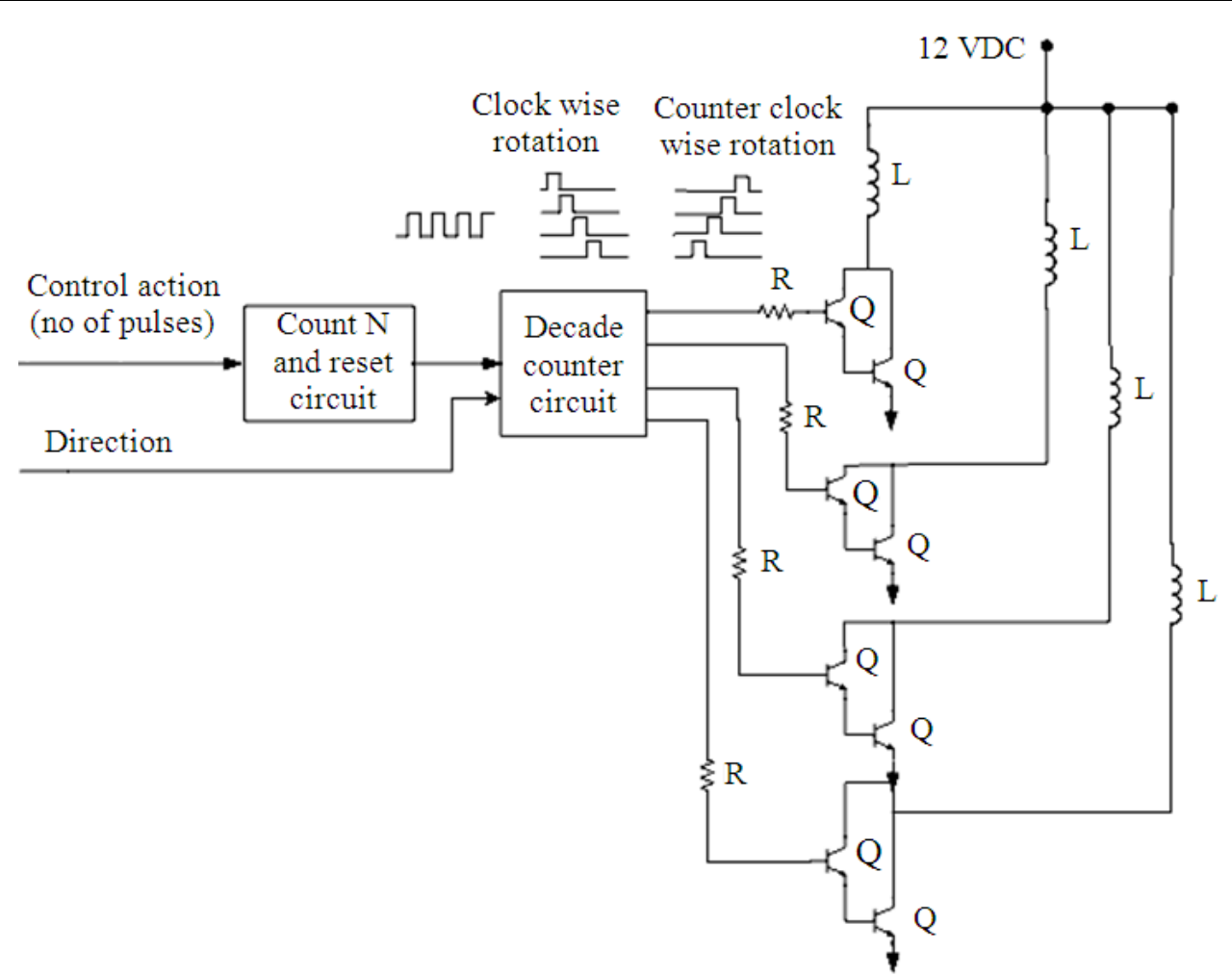

Fig. 4. Stepper motor control circuit

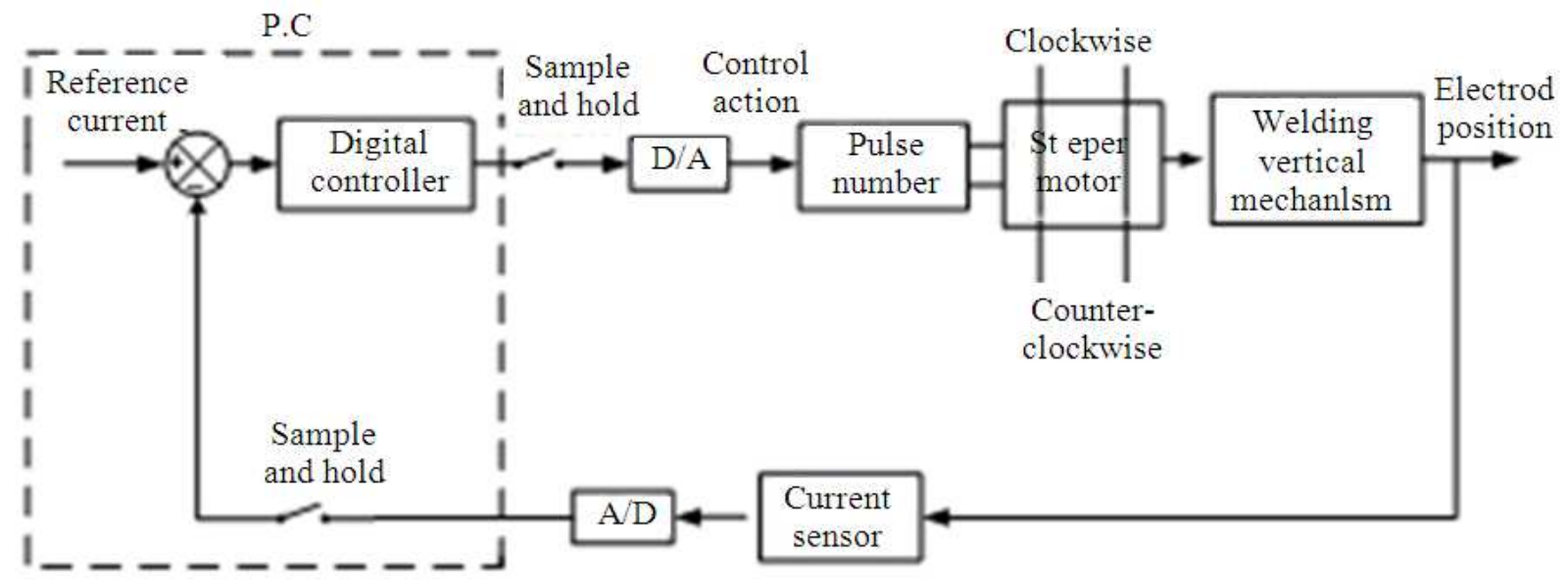

Fig. 5. Control loop for weld current control

Input to these control has been provide by using sample and hold circuit at the output of 12 bit external $\mathrm{A} / \mathrm{D}$ convertor. This $\mathrm{A} / \mathrm{D}$ convertor converts the output of current to voltage sensor implemented in feedback loop. The 12 bit $\mathrm{A} / \mathrm{D}$ convertor ensures the resolution of current down to $20 \mathrm{~mA}$. Controller output, based on operator decided reference value, is fed back to stepper motor control circuitry by using $\mathrm{D} / \mathrm{A}$ convertor.

A block diagram representation of a modified PID controller is shown in Fig. 6. PID algorithm can be explained (Vukic and Kuljaca, 2002) by a simple equation as:

$$
N_{s}=K_{p}\left(E_{t}+\frac{1}{T_{i}} \int_{0}^{t} E_{t} \cdot d t+T_{d} \frac{d E_{t}}{d t}\right)
$$

where, the error, $E_{t}$, describes, in our case, the percentage deviation of electrode position from the reference, relative to full reference electrode position. $E_{t}$ can be expressed as Equation 2: 


$$
E_{t}=\frac{y_{\text {ref }}-y}{y_{\text {ref }}}
$$

Figure 6 shows the schematic of PID controller with anti wind up scheme. The fine tuning of controller parameters has been selected to be performed by ZiglerNicholos frequency response method (Zicslen and Nichols, 1942). It has been observed that in steady state unavoidable oscillations of electrode which are mainly due to inherited friction in $\mathrm{X}-\mathrm{Y}$ mechanism which cause an overshoot in the tuned parameter. These overshoots can be associated with the integral part of the PID controller. This is due to over accumulation of the response in integration when mechanical control gets saturated while trying to reach the maximum in all axes number of motor steps.

In order to avoid these overshoot in the parameters, anti-windup scheme has been implemented. The use of back calculation form of anti-windup scheme allows reducing the integral action so that the motor motion avoids saturation.

The overall anti-windup PID control algorithm can be explained as Equation 3 to 5:

$$
N_{s}=K_{p}\left(E_{t}+\frac{T_{s}}{T_{i}} E_{\text {sum }}+T_{d}\left(\frac{E_{t}-E_{t-1}}{T_{s}}\right)\right)
$$

Where:

$E_{s u m}=\sum_{t=0}^{t}\left[E_{t}+\alpha_{u}\left(N_{s, a c t}-N_{s}\right)\right]$

And:

$N_{s, a c t}=\left\{\begin{array}{ll}+N_{\max }, & N_{s}>+N_{\max } \\ -N_{\max }, & N_{s}<-N_{\max } \\ N_{s}, N_{\max } & <N_{s}<+N_{\max }\end{array}\right\}$

where, $+N$ max and $-N$ max are max number of motor steps per control cycle in clock wise rotation and anti clock wise rotations respectively (127 step each step takes 1.80). $\alpha_{u}$ is a windup relaxation factor and is taken around 0.05 .

Integral reset method was used to reduce the steady state oscillation. This is provided by a little modification to the PID scheme as shown in Fig. 8. In this method, integral action is set to half and error integration is set to zero, when the error is oscillating within certain accepted value, $E_{\max }$ and integration error approaches a certain maximum value, $E_{\text {sum } \text { max }}$.
Based on which finally the controller action is corrected as Equation 6 and 7:

$$
\begin{aligned}
& N_{s, a c t}=\left\{\frac{N_{s, a c t}}{2},\left|E_{t}\right|<E_{\max } \&\left|E_{\text {sum }}\right|<E_{\text {sum, } \max }\right\} \\
& E_{\text {sum }}=\left\{0,\left|E_{t}\right|<E_{\text {max }} \&\left|E_{\text {sum }}\right|<E_{\text {sum, max }}\right\}
\end{aligned}
$$

The values of $E_{\max }$ and $E_{\text {sum } \max }$ are constant and chosen to minimize the steady state error oscillation.

\section{Controller Parameters Optimization}

Using Ziegler-Nichlos frequency response method, optimization of control parameters $\left(K_{p}, T_{i}, T_{d}\right)$ was first carried out for a step input of $60 \mathrm{~A}$. To produce oscillatory response, the minimum value of pure gain was found to be 65 , with frequency of oscillation being $1.5 \mathrm{~Hz}$, the integral time constant being $0.5 / 1.5$, i.e., $0.33 \mathrm{~s}$, with the derivative time constant of $0.125 / 1.5$, i.e., 0.08 s. There is interference between the frequency of oscillation caused by system instability and sticking. This is due to sticking phenomenon encountered during welding. Hence fine tuning of the controller parameters was carried out by applying changes to $T_{i}$ and $T_{d}$ until the second overshoot is one fourth the first. Also the parameter $T_{d}$ was always taken as a quarter of $T_{i}$. After these calculations, the controller parameters were calculated to be $K_{p}=22, T_{i}=0.1, T_{d}=0.05$. Several square and sinusoidal inputs tests were conducted and the Integral Time of Square Error (ITSE) was calculated to fully optimize the system. Finally, the optimized controller parameters were kept as $K_{p}=22, T_{i}=0.1 \mathrm{~s}, T_{d}=0.05 \mathrm{~s}$. These values were fixed and applied for all test cases.

\section{Computer Program}

Figure 7 shows the computer program interface used to control the vertical motion of the welding electrode. There are three modes of motion, the first is the up and down manual motion where the number of motor steps are to be inputs. The second is the modified PID control action. This mode is activated soon after the weld nugget is stably formed. The control parameters $\left(K_{p}, T_{i}\right.$ and $\left.T_{d}\right)$ are set to the nominal preset values. However it can be varied online while the welding process is progressing by scrolling the required parameter. The third is the ONOFF mode. This mode was essential to commence the weld nugget. The accumulative action of the integral control was not suitable for this mode since it causes the welding electrode to stick with the work piece so that the welding never succeeds. 


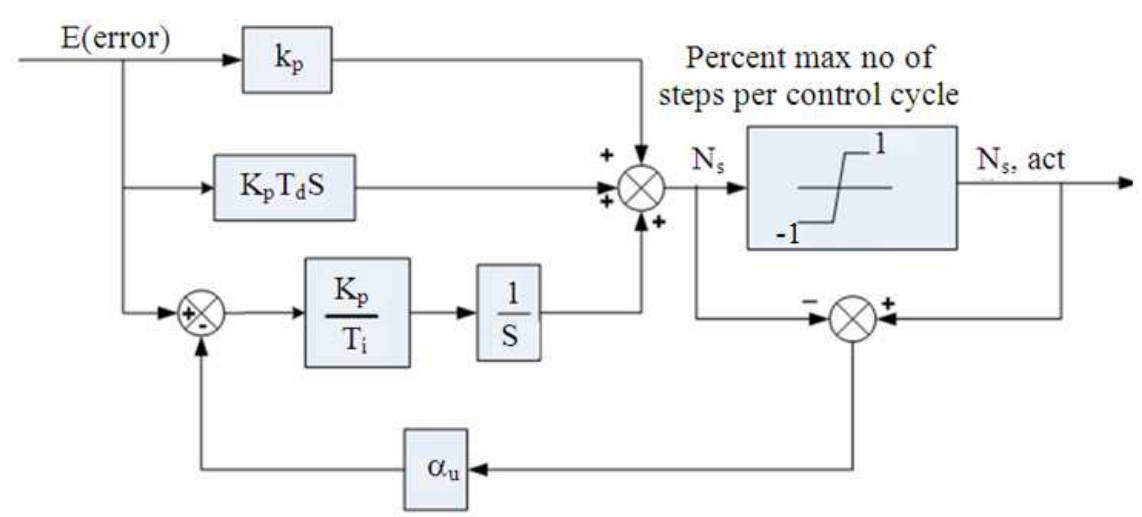

Fig. 6. PID controller with anti windup scheme

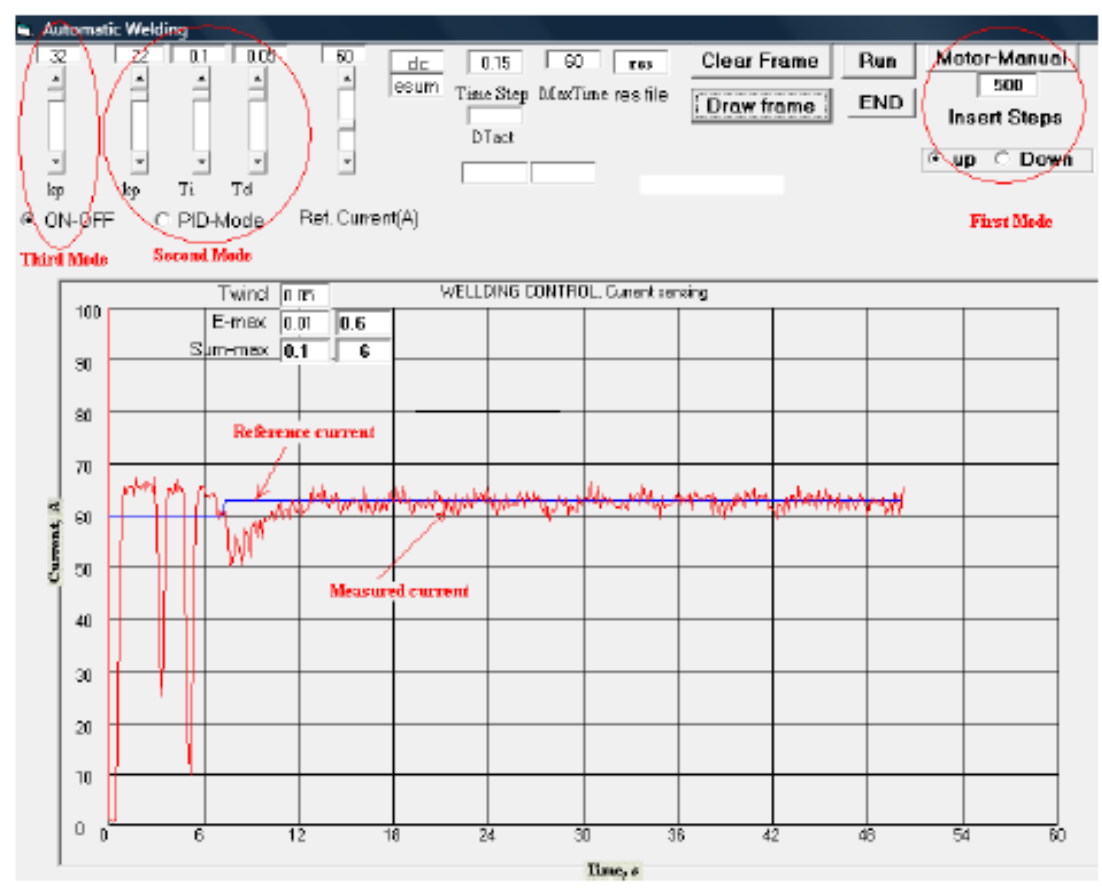

Fig. 7. Computer program interface
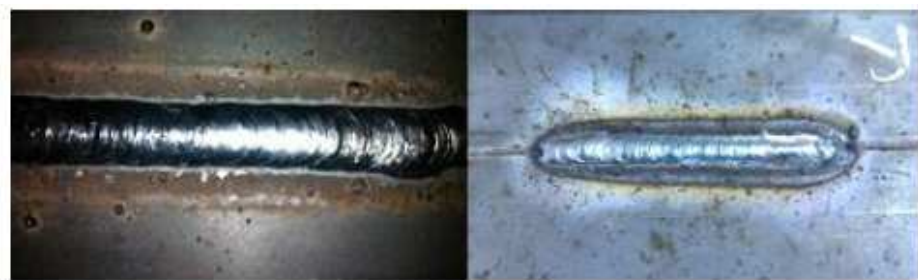

Fig. 8. A weld on a flat surface using the automatic control system

\section{Results}

After the construction of the apparatus and writing of the control program, the final step was to run the experiment and carry out welding of the joints with flat surfaces and as well as of irregular surfaces. The weld joints are shaped as V-groove surface.
Figure 8 shows two weld tests on flat surface using the automatic control system. High welding quality with homogeneous metal filling and heat transfer envelope is achieved.

A comparison between automatic and manual weld joints on a curved surface is shown in Fig. 9. The high quality of the automated weld over the manual one is 
very obvious. The manual weld joint obviously suffers from non symmetry of metal filling

Figure 10 shows the response signal on current feedback control for a flat welding sample. The initial unsteady part of the signal is due to the on-off of the system. The later part of the signal shows a steady state response of the system due to continuous mode modified PID control. The standard deviation of the signal in continuous mode is within $\pm 1.45 \mathrm{~A}$. For the optimum case, the proportional time constant gain value is 22 , the derivative time constant is $0.1 \mathrm{sec}$, the integral time constant being $0.05 \mathrm{sec}$.

Figure 11 shows the actual signal on current feedback control for a curved welding sample. The initial unsteady part of the signal is due to the on-off. The signal stabilizes later. The signal is very stable and follows a constant current of about $65 \mathrm{~A}$ while the welding is following the upward part of the curved part. However during the welding of downward slope of the part, it can be seen that there is a slight deviation of the signal in the later part of the signal. This slight deviation is due to limitation of the motors as the welding rod tries to speed up during its downward descent. There are two phenomena taking place during the downward descent. First the length of the welding rod has shortened and second it has to travel a downward slope. The motor speed has to compensate for these two causes. The limitation of motor speed is responsible for the slight deviation shown in Fig. 7. The standard deviation of the signal in continuous mode is within \pm 1.35 A. For the optimum case, the proportional time constant gain value is 20 , the derivative time constant is $0.08 \mathrm{sec}$, the integral time constant being $0.05 \mathrm{sec}$.

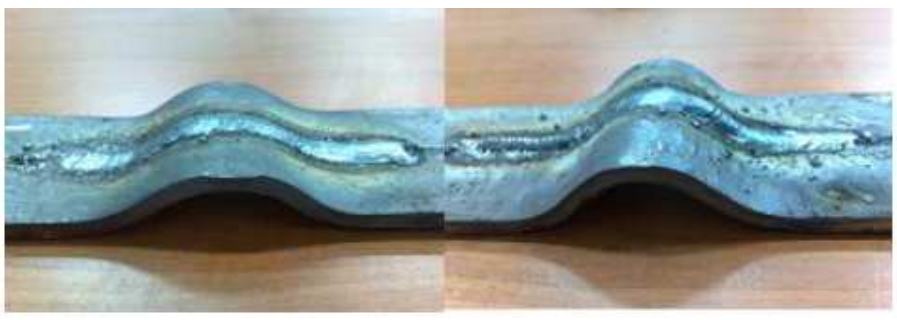

Fig. 9. A weld on an irregular surface

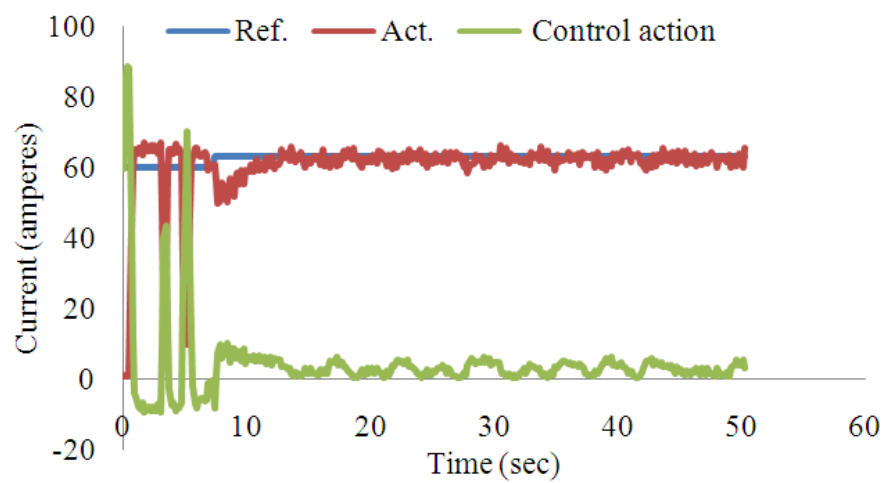

Fig. 10. Response signal on current feedback control for a flat welding sample

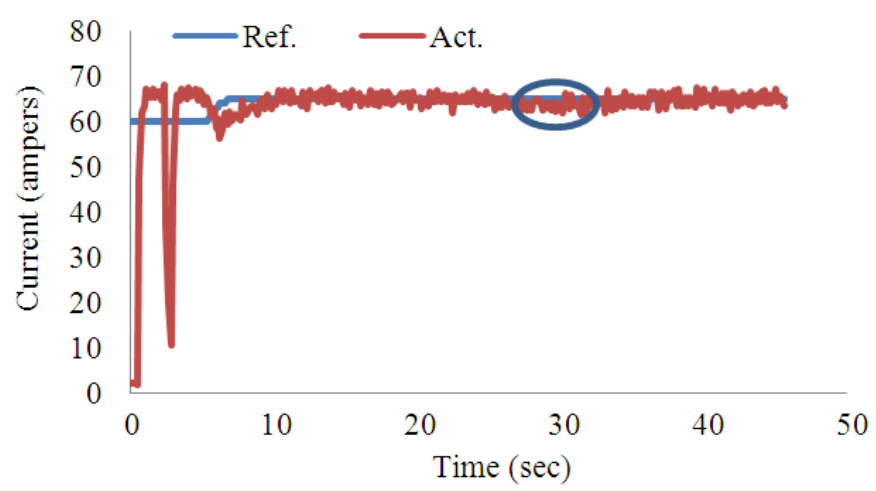

Fig. 11. Actual signal on current feedback control for a curved welding sample 


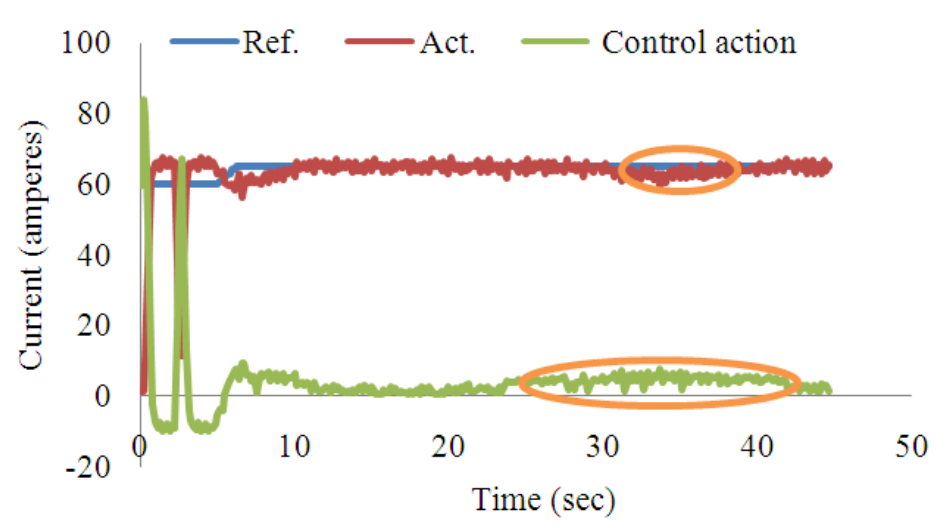

Fig. 12. Response signal on current feedback control for a curved welding sample

Figure 12 shows response signal on current feedback control for a curved welding sample. It can clearly be seen that as the actual signal is coming down the response is increasing proportionately showing excellent compensation by the feedback control system. The standard deviation of the signal in continuous mode is within $\pm 1.52 \mathrm{~A}$. For the optimum case, the proportional time constant gain value is 20 , the derivative time constant is $0.08 \mathrm{sec}$, the integral time constant being $0.08 \mathrm{sec}$.

\section{Discussion}

The above experiments also show the optimum parameters working well for the flat as well as the curved welded parts. It might also be noted in the above figures that the reference value of current was initially set at $60 \mathrm{~A}$. Later it was changed deliberately to $65 \mathrm{~A}$ to test the response of the system. As can be seen, the system responded well to this change in reference value. The experimental Welding device has successfully been controlled to obtain uniform thickness of the welding under any operating conditions, especially in uneven surfaces. This provides a new technique which can be used with accuracy in high-quality welding operations of great complexity, such as welding pipelines, doing welding on ships and spacecrafts. The control circuitry is connected to the computer and the welding machine. This results in the production of strong joints with homogeneous microstructure along the welding work area. This research will help in the development of controlled electric arc welding methods. This will greatly help oil companies, shipping and military sectors to overcome the difficulties they face during welding operations.

\section{Conclusion}

This research demonstrates excellent control of welding process through electronic circuits with controller programs which have high accuracy and are capable to keep constant distance between the weld piece and the welding rod. This is done by controlling the current to the welding arc. The equipment is capable to make uniform welding on the flat surface as well as on curved surface. Control is well exercised during the motion of weld rod in downward slopes. The control is also been demonstrated to work on moving and vibrating surfaces. It was found that the control system works with an accuracy of $\pm 28 \mu \mathrm{m}$ for a $1.01 \mathrm{~mm}$ weld thickness by controlling the current at 60 A with a standard deviation of $\pm 1.45 \mathrm{~A}$. The research demonstrates successful implementation of control leading to uniform welding joints with uniform and constant thickness. This research shows excellent feedback control even when the input signal is changed from 60 to $65 \mathrm{~A}$. For the optimum case, the proportional time constant gain value is 22 , the derivative time constant is $0.1 \mathrm{sec}$, the integral time constant being $0.05 \mathrm{sec}$. The limitations of this method are instances where there is too much vibration during the welding process, as it will affect the feedback control loop. This method will provide uniform temperatures that will lead to uniform microstructures, which in turn will lead to uniform mechanical properties throughout the weld area. The future prospect of this research is adaptation by industry for automation of welding process, resulting in better control over the thickness and uniformity of welding in cases involving curvature and vibrating instances.

\section{Acknowledgement}

The researchers gratefully acknowledge the technical and financial support provided by Qassim University and Buraydah College of Technology.

\section{Funding Information}

This research was funded by Buraydah College of Technology Project Number 2345b. 


\section{Author's Contributions}

All the authors have participated equally in the research work as well as writing of the manuscript. The main benefit and contribution of this research will be enhanced automation of the welding process in industry, with improved control over its uniformity, especially while welding around circular objects and during vibrating or unstable conditions.

\section{Ethics}

The authors confirm that this article is original and contains previously unpublished material. The corresponding author verifies that other authors have read and approved the manuscript and no ethical issues are violated.

\section{References}

Anzehaee, M.M. and M. Haeri, 2011. Welding current and arc voltage control in a GMAW process using ARMarkov based MPC. Control Eng. Pract., 19: 1408-1422. DOI: 10.1016/j.conengprac.2011.07.015

Astrom, K.J. and T.H. Hagglund, 1995. New tuning methods for PID controllers. Proceedings of the 3rd European Control Conference, (ECC' 95), Rome, pp: 2456-2462.

Bae, K.Y., T.H. Lee and K.C. Ahn, 2002. An optical sensing system for seam tracking and weld pool control in gas metal arc welding of steel pipe. J. Materials Process. Technol., 120: 458-465. DOI: 10.1016/S0924-0136(01)01216-X

Bingül, Z., G.E. Cook and A.M. Strauss, 2000. Application of fuzzy logic to spatial thermal control in fusion welding. IEEE Trans. Industry Applic., 36: 1523-1530. DOI: $10.1109 / 28.887202$

Chen, J.C. and C.X. Pan, 2011. Welding of Ti-6Al-4V alloy using dynamically controlled plasma arc welding process. Trans. Nonferrous Metals Society China, 21: 1506-1512. DOI: 10.1016/S1003-6326(11)60888-1

Doumanidis, C. and Y.M. Kwak, 2002. Multivariable adaptive control of the bead profile geometry in gas metal arc welding with thermal scanning. Int. J. Pressure Vessels Pip., 79: 251-262. DOI: 10.1016/S0308-0161(02)00024-8
Doumanidis, C.C., 1993. Multiplexed virtual torch and distributed-parameter control of automated welding. Proceedings of 2nd IEEE Conference on Control Applications, Sept. 13-16, IEEE Xplore Press, Vancouver, pp: 33-40. DOI: 10.1109/CCA.1993.348310

Fridenfalk, M. and G. Bolmsj, 2002. Design and validation of a sensor guided robot control system for welding in shipbuilding. Int. J. Join. Materials, 14: 44-55.

Karafi, M.R., R. Narimani, Y. Hojjat and M. Gheybi, 2010. Study on automatic control of arc gap in robotic TIG welding. Int. J. Adv. Manufact. Technol., 50: 953-960. DOI: 10.1007/s00170-010-2564-Z

Kima, I.S., J.S. Sona, S.H. Leeb and P.K.D.V. Yarlagadda, 2004. Optimal design of neural networks for control in robotic arc welding. Robot. Comput. Integrated Manufact., 20: 57-63. DOI: 10.1016/S0736-5845(03)00068-1

Li, P. and Y. Zhang, 2001. Robust sensing of arc Length. IEEE Trans. Instrument. Measur., 50: 697-704. DOI: $10.1109 / 19.930442$

Murugana, N. and V. Gunaraj, 2005. Prediction and control of weld bead geometry and shape relationships in submerged arc welding of pipes. J. Materials Process. Technol., 168: 478-487. DOI: $10.1016 /$ j.jmatprotec.2005.03.001

Nied, H.A. and R.S. Baheti, 1986. ARC welding adaptive process control system. General Electric Company.

Umeagukwu, C. and J. McCormick, 1991. Investigation of an array technique for robotic seam tracking of weld joints. IEEE Trans. Indust. Electron., 38: 223229. DOI: $10.1109 / 41.87591$

Umeagukwu, C., B. Maqueira and R. Lambert, 1989. Robotic acoustic seam tracking: system development and application. IEEE Trans. Indus. Electron., 36: 338-348. DOI: 10.1109/41.31496

Vukic, Z. and O. Kuljaca, 2002. Lectures on pid controllers.

Wang, Z.Z., Y.M. Zhang, X.J. Ma, 2011. Machine recognition of laser reflection from gas metal arc weld pool surfaces. J. Manufact. Sci. Eng., 133: 1-8. DOI: $10.1115 / 1.4004498$

Zhang, Y.M. and Y.C. Liu, 2007. Control of dynamic keyhole welding process. Automatic, 43: 876-884. DOI: 10.1016/j.automatica.2006.11.008

Zicslen, J.G. and N.B. Nichols, 1942. Optimum setting for automatic controllers. Trans. ASME, 64: 759-768. 